\title{
Making prevention pay
}

\author{
Alan Dove \\ Funding for biodefense is spurring new vaccine and anti-infective programs at several biotech companies.
}

Vaccine development has traditionally been a lengthy pursuit. Protracted development times, a high liability risk (vaccines are given to healthy people) and only a low rate of return have curbed the enthusiasm of big companies for vaccine R\&D. Even if the worldwide vaccine market grows to $\$ 10$ billion by 2006 (ref. 1), as predicted by Merrill Lynch (New York), it will represent only a fraction of the revenues on drugs. But the availability of funding from the US government's biodefense program is making biotech companies take a closer look. The result is a slew of novel treatments and technologies for speeding up the development of new vaccine candidates (Table 1).

\section{Reverse vaccinology}

In its simplest form, a vaccine is made from killed pathogen injected directly into a person, spurring the production of antibodies against the exposed antigens on the pathogen's surface. Unfortunately, a microbe's surfaceexposed antigens are often ineffective in eliciting protective immunity. In a refinement of this technique, vaccinologists have purified protein subunits of their targets and injected these subunits into laboratory animals or even human volunteers to try to identify the best antigens. In the 1980s, the application of genetic engineering also allowed the first recombinant subunit vaccines to be produced, circumventing the problem of contamination by blood components or products. Results have been mixed. For many pathogens, the most antigenic proteins may be expressed at very low levels, complicating identification and purification, or the purification procedure may destroy the antigen's structure.

In another traditional technique, first pioneered by Albert Sabin in the 1950s, a

Alan Dove is a freelance writer based in New York.

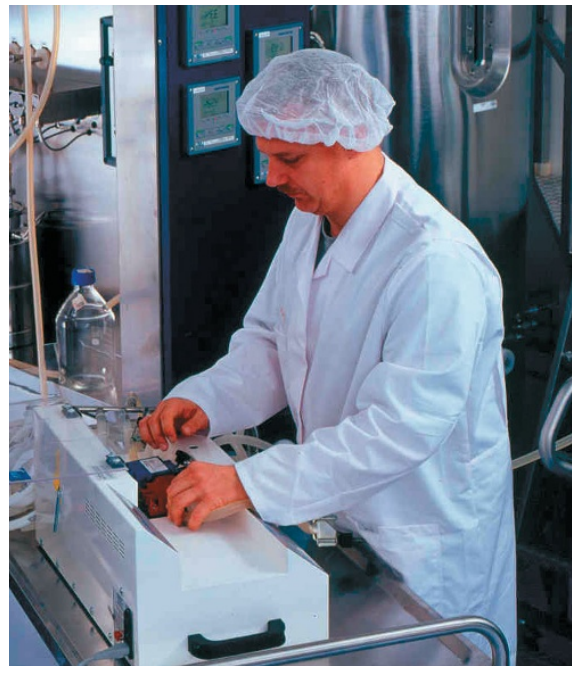

screens and animal tests identifies the most immunogenic products, which can then form the basis of an experimental vaccine.

Chiron Vaccines (Oxford, UK), which coined the term 'reverse vaccinology', has already demonstrated the method's potential. The company has a conjugated subunit vaccine that targets type $\mathrm{C}$ meningococcal disease, which is caused by Neisseria meningitidis. "Meningitis $\mathrm{C}$ has been almost eradicated in the UK with the vaccine," says Rob Budge, a spokesman for Chiron, who adds that the product, called Menjugate, is in phase 3 clinical trials in the United States. Chiron has also used reverse vaccinology to develop a series of other products, including a meningitis type $\mathrm{B}$ vaccine tailor-made to combat an unusual strain of the bacterium that has plagued New Zealand for the past 13 years.

Vaccine production enters the 21 st century. Technician making vaccine in mammalian cell culture. Image courtest of Chiron (Emoryville, CA, USA)

pathogen is repeatedly passed through different tissue culture and animal hosts until its virulence is bred out. Though Sabin's polio vaccine is the cornerstone of the World Health Organization's (WHO; Geneva) campaign to eradicate that disease, attenuated vaccines for other diseases have been difficult to develop and deliver. One common problem is that live vaccines can sometimes mutate back to virulent forms, causing the very disease they were supposed to prevent.

The advent of whole genome sequencing, however, has led some vaccine researchers to pursue 'reverse vaccinology.' Instead of starting with the whole organism, this approach begins with the genome sequence of a pathogen. Researchers then compare the sequence with the sequences of known antigens and toxins to identify likely vaccine antigens, then use recombinant expression systems to express candidate genes. A series of
Reverse vaccinology requires whole genome sequence information, but there is no shortage of that. Since most viral genomes are small, nearly all of the medically important ones have already been fully sequenced. Now, more complex genomes are rapidly piling up in public databases. Just counting sequencing projects supported by the US National Institute for Allergy and Infectious Disease (Bethesda, MD, USA), some four dozen major bacterial and protozoan pathogens, and at least one arthropod disease vector, have had their genomes completely sequenced. Dozens of additional sequencing projects are underway (Table 2).

Besides sequence gazing, complete genomes also enable transcript profiling, which can help identify gene products associated with virulence or invasiveness. Bacteria and protozoans often express virulence factors only in certain cell types or under particular environmental conditions, so a comparison of expression profiles could highlight promising vaccine and immunotherapy targets. This approach is still quite new, but transcript profiling chips for a few bacterial pathogens 
are now becoming available, and more are expected as genome sequencing efforts progress $^{2}$.

\section{Directed evolution}

Other companies are taking technologies already applied to drug development and adapting them to vaccine and anti-infectives programs. Diversa (San Diego, CA, USA), for example, is best known for its directed evolution technique, which entails generating a wide range of variations in a protein's amino acid sequence, then selecting variants with desired characteristics. Having enjoyed some major successes with enzymes, such as heatstable DNA polymerases for PCR and novel nitrilases for chiral chemical synthesis, Diversa is now looking at immunoglobulins. "We've already started working on a number of antibodies, and shown that we can...actually rebuild the antibody if you like into this mosaic antibody, which is far superior," says Gary Woodnutt, senior vice president of pharmaceutical research and development at Diversa (Fig. 1).

The immune system naturally carries out a similar selection process on antibodies, but Woodnutt argues that moving the rearrangements to a test tube makes the process easier to direct and monitor, potentially shortening development time.
Other companies are also borrowing a page from Darwin to develop new vaccines. Maxygen (Redwood City, CA, USA), for example, uses a directed evolution strategy to systematically select improved antigens and therapeutic proteins. In the vaccine market, the company's two lead products are a therapeutic colon cancer vaccine and a vaccine against dengue fever that is designed to protect against all four serotypes of the virus. Both products are now in preclinical development.

\section{Special delivery}

Producing a high-affinity antibody is a good first step, but ultimately a vaccine must be manufactured in large quantities and delivered efficiently to patients. Although some companies are focusing on production systems (see Box 1), others are trying to develop general-purpose delivery systems that can be adapted to a variety of immunizations.

One approach harkens back to the oldest vaccination system, in which Edward Jenner used vaccinia virus to deliver cross-protective antigens against smallpox. With a better understanding of the biology behind that vaccine, researchers have modified vaccinia virus to deliver the antigens of other pathogens, such as rabies virus. As a large DNA virus, vaccinia is easily engineered to carry additional antigen genes. Taking advantage of the approach, InCell (San Antonio, TX, USA) is developing a modified vaccinia Ankara virus not associated with many of the adverse events of older strains to create a smallpox vaccine that can be administered orally, with the potential to elicit strong mucosal and systemic immunity.

There is plenty of room for other viruses in the market, though, since patients immunized with one vector may develop antibodies against the vector itself, making subsequent vaccinations less effective.

Alphavax (Research Triangle Park, NC, USA) uses a disabled Venezuelan equine encephalitis virus as a delivery and expression system. Like vaccinia, the company's recombinant virus, which can be manipulated relatively easily in culture, should be able to elicit a robust immune response against virtually any target.

"Scores of genes from different diseases...have been engineered into this system, not just at Alphavax, but at different academic institutions and at [the US Army research facility] Fort Detrick, so it's a very flexible and adaptable system," says Peter Young, CEO of Alphavax. Besides shortening the preclinical development process, using similar systems for many vaccines might help reduce some of the inherent risks of the

\section{Table 1 Selected biotech companies working on biodefense vaccines}

\begin{tabular}{|c|c|c|}
\hline Company (location) & Biodefense/vaccine strategy & Development phase \\
\hline Avant Immunotherapies (Needham, MA, USA) & Bacterial vectors for antigen delivery & Phase 3 \\
\hline Alphavax (Research Triangle Park, NC, USA) & $\begin{array}{l}\text { Venezuelan equine encephalitis virus } \\
\text { vectors for antigen delivery }\end{array}$ & Phase 1 \\
\hline Chiron (Emeryville, CA, USA) & $\begin{array}{l}\text { Meningococcal vaccines; improved production } \\
\text { methods for influenza virus vaccines }\end{array}$ & $\begin{array}{l}\text { EMEA approved for use } \\
\text { in the UK }\end{array}$ \\
\hline Coley Pharmaceuticals (Wellesley, MA, USA) & $\begin{array}{l}\text { CpG-containing oligonucleotides as } \\
\text { general-purpose vaccine adjuvants }\end{array}$ & Phase 2 \\
\hline Corixa (Seattle, WA, USA) & Immune stimulatory molecules & Preclinical \\
\hline Diversa (San Diego, CA, USA) & Directed evolution of antitoxin and antimicrobial antibodies & Preclinical \\
\hline EluSys (Pine Brook, NJ, USA) & $\begin{array}{l}\text { Heteropolymer antibody conjugation system for antitoxins and } \\
\text { antimicrobials; Bacillus anthracis mAb }\end{array}$ & Preclinical \\
\hline GenPhar (Mt. Pleasant, SC, USA) & Adenovirus vectors for antigen delivery & Phase 1,2 \\
\hline Hematech (Sioux Falls, SD, USA) & Production of antitoxins and antimicrobials in transgenic/cloned cattle & Preclinical \\
\hline Human Genome Sciences (Rockville, MD, USA) & Bacillus anthracis mAb & Preclinical \\
\hline ID Biomedical (Vancouver, BC, Canada) & $\begin{array}{l}\text { Combination nasal delivery system and adjuvant made from nanospheres } \\
\text { of bacterial proteins; peptide subunit vaccines }\end{array}$ & Phase 2 \\
\hline Maxygen (Redwood City, CA, USA) & Directed evolution of recombinant antigens for subunit vaccines & Preclinical \\
\hline Omrix Biopharmaceuticals (Tel Aviv, Israel) & Immunoglobulin against smallpox virus & $\begin{array}{l}\text { Approved (on market; } \\
\text { defense agency stockpiles) }\end{array}$ \\
\hline VaxGen (Brisbane, CA, USA) & Recombinant subunit vaccine against Bacillus anthracis & Phase 1 \\
\hline
\end{tabular}


vaccine business. "Of course, as we build an increasingly robust regulatory and clinical foundation for the technology generally, I think that will increasingly facilitate the subsequent development and review of additional product applications," says Young.

Another advantage of using a virus to express an antigen in host cells, rather than just injecting the antigen, is that cellular expression often produces a cytotoxic immune response as well as an antibodymediated response. For viral infections especially, the cytotoxic response is often the primary means of clearing the pathogen. In this respect, viral vectors offer many of the benefits of live, attenuated viral vaccines without the potential side effects. Steven Projan, assistant vice-president for discovery research at WyethAyerst Research (Philadelphia, PA, USA) is enthusiastic about the approach: "A nonreplicating viral vector that can give you some rounds of gene expression without having the potential for an outbreak of viral infection-I think this is going to be perhaps the most important technology in vaccine development in the future."

Alphavax's lead HIV vaccine entered clinical trials last year, but biodefense is also a

\section{Box 1 Barnyard immunology}

Instead of trying to reverse-engineer pathogens (see main text), some companies are updating classical strategies with the tools of biotechnology. One very old technique for manufacturing immunotherapies against toxins is to inject an animal-often a horse - with the target agent, then use the animal's serum directly as an antitoxin. The approach can be effective, but it is crude, its utility often limited by the massive immune response a patient develops against the entire foreign antibody.

Using transgenic and cloning technology, Hematech (Sioux Falls, SD, USA) is now trying to bring the barnyard strategy to biodefense. "Our production system is a cow that contains a microchromosome with the full sequence of human heavy- and light-chain [antibody] genes," says James Robl, president of Hematech. The engineered cattle rearrange their human antibody genes just as they do their endogenous antibody loci. When challenged with an antigen, the cows respond with both bovine and fully human antibodies, and both types of antibodies undergo immunoglobulin class-switching and affinity maturation ${ }^{4}$.

Under a set of biodefense grants, Hematech is currently using its cows to manufacture antisera against five serotypes of botulinum toxin, as well as antigens from anthrax bacteria and vaccinia viruses. None of the products would be prophylactic vaccines, but they could supplement a rapid response to a deliberate or accidental release of pathogens or toxins. Robl envisions developing similar therapies for responding to emerging pathogens like SARS.

The cows may soon have feathered company. TranXenogen (Shrewsbury, MA, USA) and Avigenics (Athens, GA, USA) are using the eggs of transgenic chickens to produce recombinant proteins, including monoclonal antibodies and viral antigens. Since flu vaccine makers have already established high-volume production systems based on eggs, the system should be easy to scale up. Meanwhile, Origen Therapeutics (Burlingame, CA, USA) is using an approach like Hematech's, but in chickens, using the birds to generate human polyclonal antibodies.
Immunotherapeutics (Needham, MA, USA). Avant uses nonpathogenic strains of Salmonella enterica serovars Typhi and Typhimurium, and Vibrio cholerae, which survive well in the human digestive tract, to express foreign antigens to provide immunity against a pathogen of interest. The company is now conducting clinical trials on vaccines against rotavirus, cholera, typhoid fever and anthrax.

Besides providing general-purpose vaccine development systems, many of these vector-based approaches could also ease vaccine delivery. Since enteric bacteria survive in the digestive tract, for example, Avant is now working on formulating its vaccines for oral delivery. That, plus the ability to load multiple antigens into a single dose of vaccine, will be major selling points for products designed for mass immunization programs.

\section{Walking on eggshells}

In addition to improving development and delivery, new technologies may help address some longstanding difficulties in vaccine manufacturing. Every drug and vaccine faces production challenges, but the problems are perhaps most severe for influenza vaccines. Each year's vaccine is based on an educated guess made by public health officials, who try to predict in February or March which strains of the virus will be most prevalent in the next winter's flu outbreaks. Companies are then expected to have tens of millions of doses of the vaccine, made from viral cultures grown inside chicken eggs, ready by September.

At influenza vaccine production plants around the world, truckloads of eggs begin arriving in the early spring. The actual yield of vaccine doses per egg is a closely guarded trade secret, but Chiron's Budge discloses that "every day you've got coming into the facility tens or hundreds of thousands of eggs." In addition to such mundane concerns as ensuring that chicken farmers ramp up egg production early enough to meet the enormous demand, flu vaccine makers must also isolate virus strains of the right serotypes that will not be too virulent to the eggs.

Egg virulence could be a particular problem this year, since public health officials are now debating whether to include the highly pathogenic H5N1 (hemagglutinin 5/neuraminidase 1) avian influenza strain in next year's shots. The virus is deadly to chickens, and would likely grow poorly in eggs. Though just over 20 people in Southeast Asia have been infected with bird flu in the current outbreak (via direct bird-to-human contact), there is increasing fear that it could cross the species 
barrier and start a human pandemic (humanto-human spread).

Chiron is now working on a cell-based manufacturing system to bypass many of these difficulties, and expects to take a flu vaccine manufactured in cell culture into phase 3 clinical trials this year. "I think there will be some advantages in terms of time of getting the vaccine to market, and also in terms of production itself there's additional flexibility," says Budge. The new system will probably only shorten the production cycle by a few weeks, but even this could have an additional benefit for public health. In 2003, public health officials on a tight deadline guessed wrong, omitting one viral strain from the vaccine that predominated in many regions during the 2003-2004 flu season. Allowing a little more time to determine the vaccine's makeup might reduce such errors.

An alternative approach that wouldn't require switching production methods, involves a process called 'reverse genetics.' Developed by Gaithersburg, Maryland-based Medimmune Vaccines (formerly Aviron, which was acquired by Medimmune in 2002), this technology reduces the pathogenicity of the virus by creating mutants of the viral hemagglutinin gene. Researchers at the $\mathrm{WHO}$, in collaboration with several international groups, are developing a prototype vaccine for

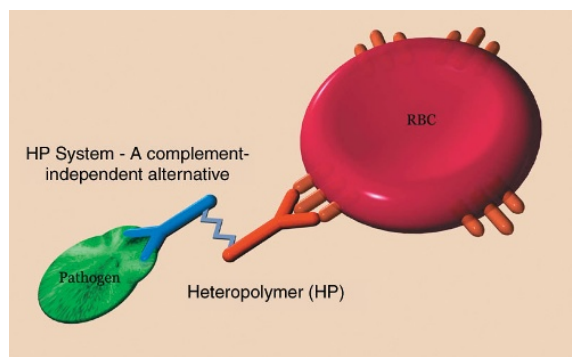

Figure 2 A heteropolymer drug. These drugs consist of two monoclonal antibodies chemically joined to one another. One antibody (blue) is targeted to the specific pathogen to be removed. The other antibody (red), targeted to a complement receptor that is found on red blood cells, carries the pathogen to the liver for destruction. (Image courtesy of EluSys, Pine Brook, NJ, USA.)

the $\mathrm{H} 5 \mathrm{~N} 1$ avian flu strain using this technique, in an arrangement with MedImmune, which holds the patent. According to MedImmune spokesperson, Jamie Lacey, the company informed WHO in 2003 that they will make the intellectual property available in the event of a pandemic.

\section{Fishing for complements}

Not everyone on the vaccine bandwagon is focusing on stand-alone treatments. Indeed, the most effective strategy for some small companies may be to find ways to boost the effectiveness of other products.

EluSys's (Pine Brook, NJ, USA) primary technology involves covalently linking an antibody against a complement receptor to an antibody against a target toxin or pathogen. When injected into the bloodstream, the twoheaded molecule tags its target for destruction by the liver, effectively clearing the foreign agent from the system (Fig. 2). "We're looking at it for vaccinia, to mitigate complications of smallpox, and then looking at it for flaviviruses like dengue, Japanese encephalitis and West Nile virus," as well as staphylococcal bacterial infections, says Linda Nardone, vice president of clinical and regulatory affairs at EluSys.

Though the linked antibodies are the company's main thrust, EluSys's lead product is actually a high-affinity monoclonal antibody $(\mathrm{mAb})$ against the protective antigen of Bacillus anthracis. So far, it has shown promising results in mice and rabbits exposed to anthrax spores. Other companies, including Human Genome Sciences (Rockville, MD, USA) and Avanir Pharmaceuticals (San Diego, CA, USA) are also working on anthrax mAbs, but clinical trials for all of these products may have to await the passage of BioShield, the mammoth biodefense funding

\begin{tabular}{|c|c|c|c|}
\hline Species & Disease & $\begin{array}{l}\text { Genome size } \\
\text { (million base pairs) }\end{array}$ & $\begin{array}{l}\text { Some known } \\
\text { (or suspected) virulence factors }\end{array}$ \\
\hline Bacillus anthracis Ames & Anthrax & 5.23 & Edema toxin, lethal toxin, capsular antigen \\
\hline Brucella melitensis $16 \mathrm{M}$ & Brucellosis & 3.29 & S-LPS (adhesins, invasin, hemolysins, LPS and OMPs) \\
\hline Brucella melitensis biovar Suis & Brucellosis & 3.31 & S-LPS \\
\hline Clostridium perfringens 13 & Gas gangrene & 3.03 & $\begin{array}{l}\text { DNAse, enterotoxin, hemolysin, hyaluronidase, } \\
\text { toxins, protease }\end{array}$ \\
\hline Coxiella burnetti RSA 493 & Q fever & 2.10 & LPS, (acid phosphatase, catalase, SOD) \\
\hline Escherichia coli 0157:H7 Sakai & Food borne gastroenteritis & 5.23 & Shiga toxin, verotoxin \\
\hline Rickettsia prowazekii Madrid E & Typhus & 1.11 & (virB, cap) \\
\hline Salmonella enterica serovar Typhi CT18 & Typhoid fever & 4.81 & Endotoxin, invasin \\
\hline Staphylococcus aureus Mu50 (VRSA) & $\begin{array}{l}\text { Community/hospital- } \\
\text { acquired infections }\end{array}$ & 2.88 & $\begin{array}{l}\text { Toxin, hemolysin, superantigens, enterotoxin, } \\
\text { lipase, Fc binding protein }\end{array}$ \\
\hline Vibrio cholerae serotype 01, biotype BTOr N16961 & Cholera & 4.00 & Endotoxin, enterotoxin, cholera toxin \\
\hline Yersinia pestis $\mathrm{CO}-92$ biovar Orientalis & Plague & 4.66 & $\begin{array}{l}\text { Siderophore, capsule, coagulase, fibrinolysin, toxin, } \\
\text { endotoxin, YOPS }\end{array}$ \\
\hline Yersinia pestis KIM5 P12 biovar Mediaevalis & Plague & 4.60 & $\begin{array}{l}\text { Capsule, coagulase, fibrinolysin, toxin, endotoxin, } \\
\text { YOPS }\end{array}$ \\
\hline
\end{tabular}

Sources: reference 5 and "BUGS" Index-Organisms (University of Florida, Department of Medical Microbiology and Infectious Diseases http://medinfo.ufl.edu/year2/mmid/bms5300/bugs/index.html).

LPS, lipopolysaccharide (LPS); S-LPS, smooth lipopolysaccharide; OMP, outer membrane protein; SOD, superoxide dismutase; Fc, immunoglobulin constant fragment; YOPS, Yersinia outer proteins. 


\section{Box 2 Where's the Teflon?}

When government officials talk about the new funding for biodefense, they often draw analogies to the space program. For many researchers, even those receiving substantial biodefense funding, the analogy is strained. "The perception is that the government is putting huge chunks of money into this area, but in reality it seems to be many small chunks, so for a company to really invest a lot of time and effort into a completely novel technology for biodefense.... is just something most companies are not doing," says James Robl, president of Hematech (Sioux Falls, SD, USA).

Biodefense grants can be used only to fund specific products that do not otherwise have commercial potential, but the underlying technologies are often modifiable for other projects. In fact, many companies now working on biodefense have simply borrowed methods that they were already developing for other, more profitable purposes. "It's a great way to help develop a technology, and it's a great way to potentially test your system and put some products on the market, but you really can't build a business plan around [biodefense]," says Robl.

Others contend that for some types of products, the new funding has been critical. "The amount of money required to come up with a new adjuvant, plus the risk of coming up with new antigens for a vaccine... makes the risk enormous and the reward capped. If government didn't step in to provide incentives, I don't think it would happen," says Robert Bratzler, president and CEO of Coley Pharmaceuticals (Wellesley, MA, USA), who adds, "I suspect in time we'll look back and say 'it's a good thing we did this."'

Steven Projan, assistant vice president of discovery research at Wyeth-Ayerst Research (Philadelphia, PA, USA), agrees that government vaccine funding is important, but argues that "the money we're investing should not be focused narrowly on a subset of pathogens we think would be used as bioterror agents, but we need to broaden our focus to the whole field of microbiology. As we learned with SARS, we never know where the next emerging pathogen is going to come from."

initiative proposed over a year ago by the Bush administration (see Box 2).

Unlike traditional vaccines, immunotherapies like those from EluSys will not induce a robust host immune response. Instead, they reduce the concentration of a pathogen or toxin in the bloodstream. "You may not cure a disease that way, but you may give the person a real shot at taking care of the infection. We all know from AIDS that viral load can be crucial," says Nardone, who adds that with antibody-based systems "anything blood-borne, we believe, can be taken out of circulation." In practice, anti-infective immunotherapies will probably be combined, both with each other and with other treatments.

\section{Lemons into lemonade}

The most obvious area for partnerships in vaccine manufacture, though, is also the least glamorous. Almost all vaccines are delivered along with chemical compounds that increase their immunogenicity, but few researchers have explored the potential for improving these adjuvants. Indeed, no genuinely new adjuvants have been approved by the US Food and Drug Administration (FDA; Rockville, $\mathrm{MD}, \mathrm{USA}$ ) in at least 20 years. Capitalizing on a serendipitous finding made by antisense researchers in the mid-1990s ${ }^{3}$, Coley Pharmaceuticals (Wellesley, MA, USA) is now hoping to fill that void.

"To our knowledge, we're the furthest along in adjuvants," says Robert Bratzler, president and CEO of Coley. The company's main product is a CpG-containing oligonucleotide, which binds to the complement 'toll-like receptor 9.' As the first companies that tried to develop antisense oligonucleotide therapies discovered, CpG-containing sequences provide a strong but nonspecific boost to the immune system. This was an enormous disappointment for the nascent antisense industry, which had hoped for a highly specific gene-silencing response, but Coley is hoping to make this lemon into lemonade.

"Years from now, I think that CpG will be the standard adjuvant that's used in all vaccines, because it has so many advantages," says Arthur Krieg, Coley's CSO. The oligonucleotides seem to provide a stronger immunological boost than competing products, like aluminum hydroxide (alum), the main adjuvant used in human vaccines for nearly 80 years. "The current FDA regimen for the anthrax vaccine is six doses over a period of 18 months," says Krieg, but with CpG adjuvants, "you get protective responses within one or at most two doses in the vast majority of people."
Interestingly, the CpG adjuvant also provides some short-term protection against a wide range of pathogens on its own, suggesting that it could be useful in the immediate aftermath of a disease outbreak, even before the specific pathogen is known. Coley has received biodefense grants to study this aspect of the compound, and the company is also collaborating with several major vaccine manufacturers.

\section{We need it yesterday}

The emergence of new approaches promises to reinvigorate vaccine research, but it may be several years before they shorten the lag between the discovery of a new disease and the production of an effective vaccine. Meanwhile, the old ways sometimes work surprisingly well, when researchers are given sufficient motivation. Severe acute respiratory syndrome (SARS), for example, is caused by a coronavirus, a family of viruses long familiar to veterinary researchers. One company, Sinovac Biotech (Beijing, China) is already starting clinical trials on a promising SARS vaccine, and several others have gotten positive preclinical results. But Sinovac's product is based on one of the oldest and simplest vaccination strategies: it contains whole, killed virus.

Even if a new vaccine works, the market is still a concern. "I think we probably share the rest of the industry's view of SARS, and that is it's very hard to predict at this stage just what kind of commercial opportunity is going to be there," says Peter Young, CEO of Alphavax (Research Triangle Park, NC, USA).

The new batch of money being promised for biodefense is supposed to quell those concerns, and although companies in the vaccine field remain wary of depending on the government dole, they are generally optimistic. Ever since Richard Nixon declared a War on Cancer in 1971, military rhetoric has been a staple of discussions about biomedical research funding. With the advent of a war on bioterror, perhaps vaccines, historically one of medicine's most powerful weapons, will finally get a long-awaited upgrade.

1. Anonymous. Vaccines seen as a $\$ 10$ billion market by 2006. Reuters News Service January 7 (2003).

2. Cummings, C.A. \& Relman, D.A. Using DNA microarrays to study host-microbe interactions. Emerg. Infect. Dis. 6, 513-525 (2000).

3. Krieg, A.M. et al. CpG motifs in bacterial DNA trigger direct B-cell activation. Nature 374, 546-549 (1995).

4. Kuroiwa, Y. et al. Cloned transchromosomic calves producing human immunoglobulin. Nat. Biotechnol. 20, 889-894 (2002).

5. Fraser, C. A Genomics-based approach to biodefence preparedness. Nature Reviews Genetics 5, 23-33 (2004) 